\title{
International Schools with English as a First Language at Elementary Schools in Indonesia
}

\author{
Edi Widianto \\ Faculty of Education \\ Universitas Negeri Malang \\ Malang, Indonesia \\ edi.widianto.fip@um.ac.id
}

\author{
Ferril Irham Muzaki \\ Faculty of Education \\ Universitas Negeri Malang \\ Malang, Indonesia \\ ferril.irham.fip@um.ac.id
}

\begin{abstract}
The development of the ability to transform in the digital world becomes a necessity in transforming ideas in the digital age. In this principle, the ability to develop sufficient knowledge is a strategic combination along with the pace of the times in Indonesia. This is despite the ideal learning background in the case study of elementary-level package learners who are concerned that digital technology is growing so rapidly. In learning in the elementary level package-learning group, the development of Information and Communication Technology (ICT) is a priority in the development of the learning process. It is a case that a system for learning in the network plays a central role in packet learning at the Elementary school level.
\end{abstract}

Keywords- international school, English language, elementary school, ICT

\section{INTRODUCTION}

Prospective elementary school teachers need a teaching material to learn the rules of Bahasa Indonesia standard in accordance with the rules that are in accordance with the Indonesian language. The problem, however, some people use English as the main communication language in the territory of the Republic of Indonesia. It is widely believed that English is an International language based on ideas [1]. English as one of the international communication languages established by the United Nations plays a strategic role in communicating. In communicating international business, English is used as the language of communication. Business agreements between countries use English according to Chin [2].

Other than that, in science exchange, English plays a strategic role. The author observes the scientific journals that exist in the world of the Internet in general use English as a language of communication. Observations, the authors conclude that English became one of the important languages in the exchange of knowledge in the international world. English besides having a strategic role in science exchange also plays an important role in business communication according to Chin [2]. An example is English is the language used in business communications, cultural exchange and science in various international forums according to Chin [2].

English is also being used as a tool to show identity. Some people use English as a language of self-existence, to raise social status in society and to look more educated. These parties use English as a Social Language in Indonesia. The use of English used by some people sometimes uses mixed language with the local language. According to the author's observations, the use of English mixed with the local language occurs because 1) Lack of pride in the local language, 2) lifestyle, and 3) is used to indicate social status in society according to Freeman [3].

So that the teaching materials of language correction in Indonesian Scientific Lecture are needed to be developed to teach the Indonesian language in accordance with the standard rules. The elementary school teacher is a teacher Indonesian official speech on learners at the elementary level in formal school. As a teacher of the first Indonesian speech in formal education, primary school teachers should be equipped with Indonesian language skills. On the other hand, language globalization has become a trend in Indonesian society according to Freeman [3]. The terms of English are easy to find in everyday life. The mixing of terms in English in Indonesian by several communities is referred to as Language according to Chin [2]. The phenomenon of using English terms that are easily encountered in everyday life can be a model for primary school students to mimic English usage that is sometimes inappropriate for its use. Primary school teachers should be able to give an example of correcting the Indonesian language that has been mixed with English according to Chin [2].

The idea in monitor theories is focused on teaching students to monitor their own process. This argument based on ideas by Singh et al. [1]. The paradigm in study language acquisition has developed based on long-term learning. In fact, this idea brings students to get closer to facts about their motivation in learning. The idea of this statement based on facts that the first language learners in Indonesia and English language. Moreover, there are some concepts here that should be seen as differing points of view as the normative paradigm. This context is where the widest range of students backgrounds. It also has to write the ideas based on the issues on educational background in Indonesia according to Chin [2].

\section{THEORETICAL REVIEW}

\section{A. Science As Discovery}

The understanding STEM can be understood as understanding the natural phenomena that occur in society. Natural phenomena that occur is a manifestation of the human attitude that seeks to map the events that occur in the environment. Kyriakos [4] explains that STEM is found by finding a link between the various phenomena that occur between the variables of cause and effect. So science is the result of discovering patterns connected between cause and effect.

So STEM with the level of objectivity can be used as a benchmark how STEM can be recorded in the community. 
Every STEM community needs to observe and verify the validity of a finding before making a generalization of an event.

\section{B. Objectivity in Natural Sciences}

In observing the phenomena that occur in nature, every scientist needs to make a definition first about an object. So there is a perception of an object before observing a thing scientifically. Natural science observes nature with an objective where an object has the same definition between one scientist and another. So by equating a definition, then humans will be able to create an understanding of certain concepts. So that will create an objective understanding.

\section{Internet}

Human life can never be separated from communicating. One medium to communicate is the Internet. The Internet is a collection of computers connected in a network that can exchange data interactively.

The Internet is a fundamental need for every human being. The Internet has become a fundamental necessity in human life. Almost in every corner of the house now as long as affordable electricity and network communications, then the Internet can be accessed. So with the human Internet can share knowledge. So as to share knowledge with others thus the Internet contributes to human life In harmony with the opinion of Taube, et al [5].

\section{METHOD}

This study has done some objectives, in this study, there are two main objectives to be discussed. The first objective is understanding multiple language exposers in language teaching. The second objectives, to discuss the influenced of communication technology like television, newspaper, social media and social networks in their study. This study has a limitation in perspective of environment that is could not be modified. The first is student could not be controlled on their interaction outside the classroom. Second, the issued that has been discussed on outer language teaching is could not be modified. The last, another subject could influence this study.

\section{RESUlt AND DisCUSSION}

\section{A. Monitor (Self-Regulation) Ability in Language Learning Context}

The idea in monitor theories is focused on teaching students to monitor their own process. This argument based on ideas by Singh et al [1] that prudential looks to the paradigm in study language acquisition have developed based on long-term learning. In fact, this idea brings students to get closer to the facts around themselves. This idea could be analyzed as a medium to enhance and raising up students motivation in learning. The idea of this statement based on facts that first language learners in Bahasa Indonesia and English language. Moreover, there are some concepts here that are should be seen as the differing point of view as the normative paradigm. This idea is should be verified in the Indonesian context, where the widest range of students backgrounds. It also has to write the ideas based on issues in the educational background in Indonesia. This background is should be confirmed on topics at local context.

\section{B. Geographical and Social Background in Language Learning}

geographical and social background. Thus, it would add differ exposers at the end will make differ ground on language abilities. Moreover this concept it should be clarified in form of noise that is able to be found in Indonesian schools. Meanwhile, it needs to clarify uses some perspective of language learning in terms of multiple exposers in the offline world and online world. In facts, it needs to consider as an effect to measure as collaboration skills. Meanwhile, some points still widely believed as external factors on language learnings. Further discussion still needs to elaborate in this context [6].

\section{Monitor Theories on Inside School}

The acquisition of language learning based on selfdiscipline by students. Meanwhile, the teachers have been though transfer words, to learn the meaning students need efforts. Freeman states that language learning has focused on transfer words and meaning, it means students have own abilities to cover their skills outside the classroom.

There also needs to require external factors outside the classroom. Those factors are requiring on fields of classrooms. It could not be compared a school in rural areas and a school in central town that is provided funds by the government. It needs to consider more on language training services. In this case, it needs extra courses to raise up students proficiencies. In facts, the social background needs to be considered as external factors according to Freeman [3].

\section{Monitor Theories Outside School}

The idea on monitor theories outside schools is based on assumption that language learning is should learn indecently outside schools. It means that baby and children learn languages by associating words and meaning [6]. It means that students should have the abilities to enhance learning outside the classroom according to Chin [2].

It means that infancies and also young learners had done training independently to associate words and meaning. The monitor capabilities are shown in infants and young learners when learning languages. The problematic cases among this facts are monitoring capabilities grows naturally. This is the key concept of monitor theories, it is a nature of human beings. The study shows that the capabilities to learn independently the babies had according to Canfield [7].

The development of the ability to transform in the digital world becomes a necessity in transforming ideas in the digital age. In this principle, the ability to develop sufficient knowledge is a strategic combination along with the pace of the times in Indonesia. This is despite the ideal learning background in the case study of elementary-level package learners who are concerned that digital technology is growing so rapidly. In learning in the elementary level package-learning group, the development of Information and Communication Technology (ICT) is a priority in the development of the learning process. It is a case that a system for learning in the network plays a central role in packet learning at the primary school level. Thus, it needs to develop English Language Teaching (ELT) concept for the tutors. 


\section{E. Use of the Internet in Primary Schools}

The Internet is an important marker in the 21 st century. With the internet, humans can share information with the world. Since the internet has been found, humans have developed the internet in various programming languages with a single purpose that makes it easy to share information on the world.

Use of the Internet can be one of the media to seek references about an event. When there is a natural disaster in an area, an expert responsible for tackling can explore to find solutions via the internet. In addition, an expert can also find the cause of the disaster so as not to happen again in the future.

The searching skills of causal factors and their consequences can be taught early on in STEM in Elementary Schools. Children in elementary school are still in the stage of play so they have a sense of curiosity towards science. Their curiosity on science can be developed to seek knowledge in cyberspace. Therefore they can be trained to practice understanding STEM as a whole in harmony with the opinion of Cresswell [8].

Learners at the primary school level need to understand that the primary sources of primary resources are important to obtain. The main source can be a benchmark for the validity of a study [8]. The Internet can be used to understand STEM in its entirety by 1) Cross-checking the knowledge gained, 2) gaining knowledge from experts, and 3) obtaining primary recourses from trusted sites. The Internet can be used to check the validity of findings in the STEM. So that child in elementary school can learn STEM by training themselves to think thoroughly against the phenomenon of cause and effect.

\section{F. Practical Use of the Internet on learning in Elementary School}

In understanding STEM a learner in elementary school needs to understand that science is essentially objective. Learners in elementary education in elementary school can learn STEM by understanding that natural science can be studied from various angles of view.

The Internet can be used by learners to seek as much knowledge as possible with teacher guides. With teacher guidance, a learner can utilize the internet as a material to gain as much knowledge as possible. Teachers can guide by standards of competence and basic competencies taught in harmony with the opinion of Creswell [8]. The practical benefit of internet for the world of education is to train students to think critically. So that a learner can examine creative problems that exist in the field with the internet objectively in harmony with the opinion of Cook, et al [9].

\section{G. STEM Education on 21 Century Use of the Internet in Primary Schools}

The 21 st century by experts is defined as the information age. Almost everyone is able to access the information they want to get through various communication technologies. So the development of STEM becomes faster. In the middle ages, STEM findings were almost dominated by certain institutions such as universities, religious institutions, and the state. People who have the right to gain access to the STEM are limited in number. So people tend to put science under other sciences.
In understanding science, medieval society sometimes uses the non- STEM approach perspective. The impact of the use of a STEM approach proved to be the main problem that is the lack of understanding of the elements of cause and effect.

So when there is an outbreak of black death, medieval society associates with the occult like witches, the curse of the ancestors and the punishment for sinning. That opinion is not entirely wrong if it is linked to getting closer to the spiritual elements. However, the issue of opinion is less able to solve the problem because the cause is not detected in advance.

That's why an understanding is needed that aims to study the paper objectively. By examining a problem objectively then a learner can see a problem not only from one cause but can be caused by various causes. The 21 st century provides an opportunity to examine the problem objectively. In the 21 st century, if found a peak it or plague, with technical information and communication can then be found $n$ references about the cause of an event and how it's handling. So that learning in the 21 st century needs to be directed to the use of information technology In line with the opinion of Stansell, et al [10] state that government, in this case, the Indonesian Ministry of Education and Culture explains three major challenges in the STEM. Ministry of Education and Culture [11] explains there are three major challenges in the future life in the field of information technology are 1) information literacy, 2) media literacy, and 3) ICT literacy. From this, it can be concluded that learning in the $21 \mathrm{st}$ Century needs to be directed to STEM-based on information and communication technology in harmony with the opinion of Kyriakos [4].

\section{H. The Problem of STEM Learning in the 21st Century}

In the process of learning STEM in the 21st century, the Internet plays a key role in explaining science. Internet use for STEM learning in the 21st century needs to be taught at the primary school level. STEM as one of the core-subjects in learning at primary school level needs to address learning challenges in the field of information and communication technology. The challenge examined in this paper is how to use the Internet to examine natural science objectively. The challenges in learning STEM, need to be taught to utilize the internet from an early age [12]. STEM in elementary schools needs to be integrated with the internet.

\section{CONCLUSION AND SUGGESTION}

\section{A. Conclusion}

It is widely believed that language has four skills, listening, speaking, reading and writing. From those skills, listening comprehension takes important roles in the first step of language teaching and learning process, especially in Indonesia, where English is a foreign language. Listening is a means of successful language learning. It is the most critical for language learning at the beginning.

\section{B. Suggestion}

English foreign language learners need model how to pronounce words, how to construct a sentence in acceptance form of English. Learners at the beginning have to imitate words and sentences based on listening media. In Indonesia, English is a foreign language; it is difficult to find exposures. 
Exposures are important for language learners since them needs the example of using language in the real situation as the compliment of design language, which is set up by the teachers.

\section{REFERENCES}

[1] L. Singh, T. J. Hui, C. Chan, and R. M. Golinkoff, "Influences of vowel and tone variation on emergent word knowledge: a crosslinguistic investigation,” Dev. Sci., vol. 17, no. 1, pp. 94-109, 2014.

[2] J. M.-C. Chin and M.-R. Huang, "A Study on the Relationships Among Distributed Leadership, School Innovative Management and School Effectiveness in Taiwanese Senior High Schools," Jiaoyu Yu Xinli Yanjiu J. Educ. Psychol., vol. 39, no. 2, p. 1, 2016.

[3] D. Larsen-Freeman, "Transfer of learning transformed," Lang. Learn., vol. 63, pp. 107-129, 2013.

[4] A. G. Kyriakos, "In Response to Kalanov: How Many Truths Exist in Science?," Prespacetime J., vol. 1, no. 5, 2010.

[5] D. Taube, O. Renn, and A. Hohlt, "14 STEM education from a comparative transnational perspective," Int. Sci. Technol. Educ. Explor. Cult. Econ. Soc. Percept., p. 191, 2015.
[6] K. Byers-Heinlein, C. T. Fennell, and J. F. Werker, "The development of associative word learning in monolingual and bilingual infants," Biling. Lang. Cogn., vol. 16, no. 1, pp. 198-205, 2013.

[7] D. W. Canfield, "The Discursive Construction of Language Teaching and Learning in Multiuser Virtual Environments," 2016.

[8] J. W. Creswell, "Collecting qualitative data," Educ. Res. Plan. Conduct. Eval. Quant. Qual. Res. Fourth Ed Boston Pearson, pp. 204-35, 2012.

[9] E. Cook, E. A. Teaff, and L. J. Cook, "A Collaborative Vision: Partnering with STEM Faculty to Teach Visual Literacy Through Multimedia Research Presentations," Internet Ref. Serv. Q., vol. 20, no. 3-4, pp. 63-88, 2015.

[10] A. Stansell, B. Quintanilla, E. Zimmerman, and T. Tyler-Wood, "Teaching engineering concepts through a middle school transmedia book," TechTrends, vol. 59, no. 2, pp. 27-31, 2015.

[11] L. Kemdikbud, "Kurikulum 2013: Pergeseran paradigma belajar abad-21," Jkt. Juni, 2013.

[12] M. Castells, Networks of outrage and hope: Social movements in the Internet age. John Wiley \& Sons, 2015. 